\title{
UM OLHAR SOBRE O IMPEACHMENT DE DILMA ROUSSEFF
}

\author{
Resenha de: ALMEIDA, Rodrigo de. À sombra do \\ poder: Bastidores da Crise que Derrubou Dilma \\ Rousseff. São Paulo: Leya, 2016. 224p.
} Daniel de Souza Lemos*

\begin{abstract}
RESUMO
Resenha do livro do cientista político e jornalista Rodrigo Almeida, então Secretário Imprensa da Presidência da República, nos meses finais do segundo mandato de Dilma Rousseff antes de seu impedimento. À sombra do poder: bastidores da crise que derrubou Dilma Rousseff, narra os fatos que constituíram o pano de fundo da crise que pôs fim prematuramente ao segundo mandato da primeira presidenta do Brasil.
\end{abstract}

Palavras-chave: Dilma Rousseff; Impiechment; Golpe

$* * *$

A Revolução Russa de 1917 completou cem anos e no calor dos eventos que tiveram impacto na História John Reed - jornalista socialista estadunidense - escreveu "Dez dias que abalaram o mundo". O livro de leitura indispensável é o resultado do olhar de alguém que foi testemunha ocular daquela revolução. Anos antes, no

* Mestre em Ciência Política, graduado em História e formando em Direito, pela UFPel. Especialista em Sociologia, pela UFRGS. SEDUC RS. E-mail: danielslemos@ yahoo.com.br 
Brasil, durante a Guerra de Canudos (1896-1897), ocorrida no interior da Bahia, Euclides da Cunha presenciou parte do conflito como correspondente do jornal $\mathrm{O}$ Estado de $\mathrm{S}$. Paulo e, narrando os episódios desse importante acontecimento da história do Brasil República escreveu Os Sertões, que foi publicado em 1902.

Na história recente do Brasil, em uma posição privilegiada, diante da crise política que culminou com o impedimento do segundo mandato presidencial de Dilma Rousseff, Rodrigo de Almeida era o Secretário de Imprensa da Presidência da República, "em um governo nada afeito a se comunicar", de acordo com o próprio. Antes disso, o jornalista e cientista político doutorado pelo Instituto de Estudos Sociais e políticos (Iesp) da UERJ havia ocupado o cargo de assessor de imprensa do Ministro da Fazenda, Joaquim Levy - talvez o mais questionado de todos os ministros dos dois mandatos de Dilma Roussef. Nessa condição, como observador e partícipe do fato mais impactante da política brasileira recente, o impeachment, chamado pelos apoiadores da então presidenta de golpe, é que o autor se propõe a escrever "um livro de observação. Um registro para a história de uma época profundamente trágica para o país." (2016, pág.12)

As 224 páginas do livro de Rodrigo de Almeida estão divididas em 24 capítulos - precedidos de uma explicação - onde são apresentados os elementos que compõe o contexto geral da crise, ou das crises, que levaram à queda de Dilma Rousseff da Presidência da República. Para delinear tal quadro o autor escolhe o último dia da presidenta no exercício do mandato presidencial, ou seja, o silencioso, melancólico e quente (passaria de $30^{\circ} \mathrm{C}$ aquela quinta-feira) 12 de maio de 2016. Que foi o resultado do que Almeida chama de "a versão brasileira das dez pragas do Egito", os fatos que constituíram a crise do Governo Dilma.

Logo na "explicação", capítulo inicial do livro, Almeida enumera aquilo que em sua opinião são os dez principais episódios que compuseram o pano de fundo da crise do Governo, que foi interrompido com o impeachment:

Ao longo daqueles meses, entre a Esplanada e o Palácio, o governo viveu e padeceu sob a versão brasileira das dez pragas do Egito. Listei: inflação de dois dígitos, 
desemprego também de dois dígitos, recessão econômica, o mar de lama deixado pelo rompimento da barragem de Mariana, em Minas Gerais, o vírus Zika, a Operação Lava Jato, a delação premiada do senador Delcídio Amaral, preso no exercício do mandato, a polêmica sobre a compra da refinaria de Pasadena, a ação no Tribunal Superior Eleitoral que pedia a cassação da chapa DilmaTemer, e o processo de impeachment no Congresso. (ALMEIDA, 2016, 09)

E, então, passa a registrar as observações - colhidas nos bastidores e nas informações publicadas pela imprensa - de quem não se classifica como um "militante ou assessor ressentido", mas um auxiliar que buscou ajudar o governo e o país, dentro de seus limites subjetivos e institucionais.

\section{As equipes ministeriais do segundo mandato}

"Eleição nova, governo novo, equipe nova"

(ALMEIDA, 2016, P.41)

O ministério do segundo mandato presidencial de Dilma Rousseff foi questionado desde o início da formação. Que começou com a escolha de Joaquim Levy, para o Ministério da Fazenda. Este representava a presença do mercado financeiro no governo, e a adesão à política econômica do candidato derrotado, o neoliberal Aécio Neves, do PSDB, conforme as acusações do setor petista da coalizão governamental.

O principal apoio de Joaquim Levy para Ministro da Fazenda veio de Luiz Carlos Trabuco. Presidente do Bradesco, "homem forte de um dos maiores bancos do país" (pág. 77), pertencia à mística dinastia, de apenas quatro indivíduos, que controlou o Bradesco em 70 anos de história. Ele articulava ainda, outros empresários que afiançavam e, inclusive chantageavam o governo, pela permanência 
de Levy no cargo mais importante da economia, a saber, Carlos Jereissati, Pedro Moreira Salles e Josué Gomes da Silva.

Também compunham a equipe econômica do segundo mandato Nelson Barbosa, Ministro do Planejamento - e depois com a demissão de Joaquim Levy - da Fazenda e Alexandre Tombini, presidente do Banco Central. Estes, em várias ocasiões se engalfinharam em disputas ao longo do período em que estiveram em seus cargos. Dois exemplos destacam-se: a maneira como encaminhar o ajuste fiscal, idealizado por Levy, e a proposta de orçamento deficitário enviado ao Congresso em 2016, que o ministro da fazenda se opunha e Nelson Barbosa e Aloísio Mercadante defendiam.

Entre os petistas da equipe destacavam-se: Aloízio Mercadante, Ministro chefe da Casa Civil e, depois, Ministro da Educação; Pepe Vargas, Ministro das Relações Institucionais (depois Ministro da Secretaria dos Direitos Humanos); Miguel Rossetto, Ministro Secretário Geral da Presidência, posteriormente do Trabalho e Previdência Social; José Eduardo Cardoso, Ministro da Justiça e, depois Advogado geral da União; Gilles Azevedo, Assessor Especial; Jaques Wagner, Ministro chefe da Casa Civil (substituindo Mercadante com o agravamento da crise); Ricardo Berzoini, Ministro das Relações Institucionais (substituindo Pepe Vargas); Tereza Campello, Ministra do Desenvolvimento Social; Eleonora Menicucci, Secretaria de Políticas para as Mulheres;

Outros membros da equipe ministerial ocuparam posição coadjuvante durante o curto período do segundo governo Dilma. Destacando-se: Luís Inácio Adams, Advogado-geral da União; Aldo Rebello, Ministro da Defesa; Kátia Abreu, Ministra da Agricultura; Carlos Gabas, Ministro da Previdência Social; Eliseu Padilha, Ministro da Aviação Civil; Gilberto Kassab, Ministro das Cidades; Cid Gomes, Ministro da Educação (substituído pelo filósofo Renato Janine Ribeiro após desentendimento daquele com o deputado Eduardo Cunha); Marcelo Castro, Ministro da Saúde; Celso Pansera Ministro da Ciência e Tecnologia; entre outros.

Nomes que, nas palavras de Jânio de Freitas, "um jornalista com um olhar habitualmente mais favorável ao governo Dilma" (ALMEIDA, P.90) são "os retalhos que vêm formar um pretenso ministério não tem o mínimo de ideia e de substância" (ALMEIDA, p.90). 


\section{A oposição sai fortalecida da eleição de outubro de 2014}

“A tese virou clichê: o Brasil saiu dividido da disputa presidencial de 2014" (ALMEIDA, 2016, P.33)

A ação da oposição começou quatro dias após o anúncio da reeleição de Dilma Rousseff, no domingo dia 26 de outubro de 2014. Aécio Neves, "o candidato que não soube perder", acompanhado de seus correligionários Fernando Henrique Cardoso e José Serra, ajuizou no Supremo Tribunal Eleitoral um pedido de "auditoria especial", questionando o resultado eleitoral. A margem apertada de votos $-51,65 \%$ dos votos para Dilma Rousseff, versus os 48,36\% de sufrágios obtidos por Aécio Neves - nunca foi assimilada pelos tucanos. E, motivou ação patrocinada pelo deputado federal paulista Carlos Sampaio, do PSDB, coordenador jurídico da campanha do candidato derrotado. A estratégia adotada pela oposição foi a de questionar a legitimidade do mandato presidencial de Dilma Rousseff.

Outro flanco oposicionista ficou a cargo das lideranças parlamentares reunidas em torno de Roberto Freire, presidente do PPS, José Agripino Maia, presidente do DEM, Paulo Pereira da Silva, presidente do Solidariedade, José Luiz Penna, presidente do PV, cuja missão era avançar com o pedido de impeachment.

Conforme Almeida, o "cretinismo parlamentar" daqueles que fizeram do legislativo algoz do mandato presidencial de Dilma Rousseff, foi amplificado com a sabedoria regimental dos oportunistas da Câmara dos Deputados. Que eram liderados pelo seu então presidente, o Deputado Eduardo Cunha do PMDB, e constituíam os chamados "moralistas sem moral" denunciados nos discursos da ainda presidenta.

Além da oposição parlamentar, a presidenta enfrentava a frente única constituída por FIESP - VEM PRA RUA - PSDB, que patrocinou as ações de rua contra o governo e atraía a atenção da grande mídia. Representava o segmento social que elegeu a oposição e, deu o suporte "popular" do processo de impedimento da presidenta. 
Ao contrário de Fernando Henrique Cardoso e Luís Inácio Lula da Silva, seus antecessores na presidência, Dilma Rousseff não sabia dialogar com o legislativo, tampouco se dedicava ao "penoso trabalho de conversar com parlamentares" (p.56). Prática, esta, que sem dúvida constitui o modus operandi do presidencialismo de coalizão, que é característica maneira de governar o Brasil constituindo alianças de base parlamentar. Amplificando as dificuldades políticas do governo que perdeu, bem cedo, a capacidade de impor a agenda de governo e aprovar iniciativas que tramitavam no Congresso, o que irritava o ex-presidente Lula (p. 75)

Somada aos críticos do governo, a mídia potencializa a voz da oposição como dizia o cientista político Wanderley Guilherme dos Santos "prática habitual da imprensa de enxergar o ruim quando está bom e o péssimo quando está ruim" (ALMEIDA, 2016, p.55). Veículos da imprensa tradicionais como a Folha de São Paulo, o Estado de São Paulo, o Globo, Valor Econômico, Jornal da Globo, Jornal Nacional, entre outros engrossavam o coro do impeachment.

\section{Os aliados de ocasião e os traidores}

"era preciso criar um novo bloco de apoio no Congresso" (ALMEIDA, 2016, p. 85)

Uma das ações políticas mais frustrantes e que teve grande impacto negativo, foi a operação para construir uma maioria parlamentar que não fosse dependente do PMDB, maior partido da Câmara. Idealizada pelo Ministro Aloizio Mercadante (iniciativa nunca confirmada publicamente) e tendo como operadores para a criação de um novo partido, os ministros Gilberto Kassab, PSD, e Cid Gomes, PROS, despertou a ira dos lideres do PMDB, em especial Eduardo Cunha e Michel Temer.

Para acalmar os ânimos com o PMDB, a presidenta Dilma, entregou a articulação política do governo para o Vice-presidente Michel Temer, que auxiliado por Eliseu Padilha, começaram então a 
conspirar contra Rousseff abertamente. Isso confirmava a tese do exministro Ciro Gomes, que chamava Temer de "capitão do golpe".

A precária coalizão política que apoiava o governo Dilma era constituída pelos seguintes partidos: PT, PMDB, PTB, PR, PSD, PDT, PCdoB, PRB, e PP, ou seja, nove partidos, que com poucas exceções se encontravam divididos sobre o apoio ao governo.

\section{Conseqüências do desprezo da presidenta pela arte da política: o Impeachment}

"fazer a coisa certa depois de se esgotarem todas as demais
alternativas" Winston Churchill (ALMEIDA, 2016, 82)

Jeitoso no trato com a imprensa, boa-praça com os colegas de trabalho e bom articulador com os partidos aliados e até mesmo com os adversários, Jaques era a antítese do antecessor, Aloízio Mercadante. (ALMEIDA, 2016, p. 91)

A presidenta Dilma Rousseff começou tardiamente a fazer a coisa certa para enfrentar a crise política, a saber, trocar os ministros que tumultuavam o ambiente político por nomes que viessem contribuir com a articulação política. O primeiro nome com essa missão foi o ex-governador da Bahia, Jaques Wagner, que substituiu Aloízio Mercadante na chefia da Casa Civil da Presidência. Junto com o político baiano, Dilma Rousseff recrutou Ricardo Berzoini como Ministro das Relações Institucionais, substituindo Pepe Vargas, outro quadro muito criticado.

Outras crises de diferentes naturezas apareceram e forçaram a criação de "grupos de gestão de crise" ou grupos de trabalho (GT), cabe citar, GT da microcefalia, GT da Zika, GT do impeachment. Mas a maior de todas as crises era produzida e disseminada pelo 
presidente da Câmara dos Deputados, Eduardo Cunha, do PMDB carioca. Este ameaçava, chantageava, enfrentava, combatia e articulava contra o governo Dilma desde o dia em que a presidenta se reelegeu, e Cunha começou a preparar sua candidatura a presidência da Câmara Federal. Mesmo tendo sido procurada por Michel Temer, que temia o fortalecimento político de Cunha no PMDB, a presidenta Dilma Rousseff não deu a atenção devida ao fato.

Logo, o grande movimento do xadrez do processo de impeachment foi dado na quarta-feira, dia 02 de dezembro de 2015, quando o Presidente da Câmara dos Deputados acolheu o pedido de impeachment apresentado pelos advogados Hélio Bicudo, Miguel Reali Júnior e Janaína Pascoal. Foi o xeque-mate. O que, no entanto, nas palavras de ALMEIDA, configurava:

um processo deflagrado como um ato de retaliação, a reação indignada de uma presidente que não aceitou ser chantageada e expôs, com firmeza, uma comparação de biografias entre ela e Cunha. (ALMEIDA, 2016, p.115)

\section{Conclusão}

"Governo, aprendi, é para os fortes. E mais do que ninguém Dilma Rousseff demonstrou sua fortaleza diante das tempestades que atravessou" (ALMEIDA, 2016, p.11)

Além de Almeida se apresentar como um observador participante dos fatos que culminaram com a queda de Dilma Rousseff da presidência do Brasil, o trabalho recorda um emaranhado de fatos, que em maior ou menor grau, contribuíram para o desfecho da crise. A principal fonte utilizada por Almeida para a reconstituição dos episódios narrados foi a imprensa nacional. Os periódicos - de oposição e de situação - são mencionados em todo o livro. Este, igual os livros mencionados no primeiro parágrafo desta resenha 
constituem relevantes depoimentos. Porém, a obra de Almeida tende a ser convertido em fonte histórica de pesquisas que buscam aprofundar os fatos narrados, visto a superficialidade analítica do texto.

Ainda o autor registra com perspicácia os atributos pessoais dos protagonistas do principal evento da história política recente do país. Desde a personalidade forte de Dilma Rousseff que jamais enfrentava um tema sem ter "feito o dever de casa", estudado com afinco o assunto a ponto de desestabilizar os interlocutores menos previnidos. Até a maneira jeitosa, gentil de "dizer não" do Ministro Jaques Wagner, oposta de seu antecessor Mercadante. Ou a disciplina, capacidade de trabalho e conhecimento das regras do jogo, que marcam a personalidade de Eduardo Cunha, segundo reportagem da revista Veja.

A história política do Brasil é marcada fortemente por golpes, renúncias e deposições de quadros das elites governantes. O livro de Rodrigo de Almeida merece ser lido por abordar, mesmo que de maneira limitada analiticamente, por abordar o processo do impedimento da primeira mulher a presidir o país, porém um caso entre tantos, de violação da voz das urnas que caracterizam a história política brasileira.

RECEBIDA EM: 22/02/2017

APROVADA EM: 19/06/2018 